\title{
Low cardiovascular risks in the middle aged males and females excreting greater 24-hour urinary taurine and magnesium in 41 WHO-CARDIAC study populations in the world
}

Yukio Yamori, Takashi Taguchi, Hideki Mori, Mari Mori

From $17^{\text {th }}$ International Meeting of Taurine

Fort Lauderdale, FL, USA. 14-19 December 2009

\begin{abstract}
Background: Since taurine (T) administration was proven to decrease blood pressure (BP) and stroke mortality in stroke-prone spontaneously hypertension rates (SHRSP) in the 1980's and our WHO-coordinated CARDIAC (Cardiovascular Diseases and Alimentary Comparison) Study demonstrated that among 5 diet-related factors, namely total cholesterol (T-Cho), body mass index (BMI), sodium ( $\mathrm{Na})$, magnesium $(\mathrm{M})$, and $\mathrm{T}$ to creatinine $(\mathrm{Cr})$ ratio in 24-hour urine (24U), both $\mathrm{T} / \mathrm{Cr}$ and $\mathrm{M} / \mathrm{Cr}$ were inversely related to coronary heart disease mortalities in males and females and $\mathrm{T} / \mathrm{Cr}$ was inversely related to stroke mortalities in males and females. We further analyzed the associations of individual $\mathrm{T} / \mathrm{Cr}$ and $\mathrm{M} / \mathrm{Cr}$ levels to cardiovascular risks in the present study.

Method: From WHO-CARDIAC Study populations, 61 populations of 25 countries in the world, Japanese populations with obviously higher $24 \mathrm{U} \mathrm{T}$ excretion because of their common fish eating custom and the other populations in which both data of $\mathrm{T}$ and $\mathrm{M}$ were not available were excluded and the data of 3960 individuals from 41 WHO-CARDIAC Study populations were used for the following analyses.

Results: The means of $24 \mathrm{U} \mathrm{T/Cr}$ and $\mathrm{M} / \mathrm{Cr}$ ratios in total individual data were 639.4 and 82.8, respectively. The average of BMI, systolic and diastolic blood pressure (SBP, DBP), T-Cho and atherogenic index (Al) in the individuals with more than the means of $\mathrm{T} / \mathrm{Cr}$ or $\mathrm{M} / \mathrm{Cr}$ were significantly lower than those of individuals with less than the means. The CARDIAC Study participants were divided into the following 4 groups by these means: A (T/Cr and M/ $\mathrm{Cr} \geqq$ mean), $\mathrm{B}(\mathrm{T} / \mathrm{Cr} \geqq$ mean, $\mathrm{M} / \mathrm{Cr}<$ mean), $\mathrm{C}(\mathrm{T} / \mathrm{Cr}<$ mean, $\mathrm{M} / \mathrm{Cr} \geqq$ mean), $\mathrm{D}(\mathrm{T} / \mathrm{Cr}$ and $\mathrm{M} / \mathrm{Cr}<$ mean). The group A showed significantly lower values compared with the group D in BMI, SBP, DBP, T-Cho, and Al.

Conclusions: Cardiovascular risks were proven to be highly significantly lower in individuals who were excreting both $24 \mathrm{U} T$ and $M$, more than the averages despite differences in ethnicity and genetic background. Since $T$ and $\mathrm{M}$ are biomarkers for seafood, vegetables, soy, nuts, milk, etc., dietary custom to eat these food sources could be recommended for cardiovascular disease prevention.
\end{abstract}

\footnotetext{
* Correspondence: yamori@cardiacstudy.com

Mukogawa Women's University Institute for World Health Development,

Nishinomiya, Hyogo, 6638143, Japan

Full list of author information is available at the end of the article
}

(c) 2010 Yamori et al; licensee BioMed Central Ltd. This is an open access article distributed under the terms of the Creative Commons 


\section{Background}

WHO-CARDIAC Study is an epidemiological surveillance covering 61 regions in 25 countries that has been executed since 1985 [1,2]. This study confirmed that there was a close relation between cardiovascular diseases (CVD) and dietary customs by analyzing dietary biomarkers of 24-hour urine (24U). The amount of taurine $(\mathrm{T})$ excreted in $24 \mathrm{U}$ and the mortality rates of coronary heart diseases (CHD) were inversely correlated significantly by a regional correlation analysis [3]. Moreover, the mortality rates were found significantly lower in the regions where as much $\mathrm{T}$ was consumed as in Japan. On the other hand, when the correlation of $24 \mathrm{U}$ magnesium (M) excretion and the blood pressure (BP) was analyzed, $M$ showed inverse correlations with both systolic and diastolic BP's [4]. These investigations suggested that the risk of the CVD differed in different populations and could be influenced greatly by such environmental factors as dietary customs, lifestyles and temperature. The data so far obtained from the population averages of worldly distributed regions showed that $\mathrm{T}$ and $\mathrm{M}$ intakes might have protective effect on CVD. However, the population averages are influenced greatly by the genetic factor of the inhabitants and the environmental factors of the regions examined. In the present study, the influence on CVD risks of the dietary factors was analyzed by examining the associations of $24 \mathrm{U} T$ and $M$ excretions of individual participants with their own CVD risks disregarding their genetic backgrounds, living conditions and genders in the combined CARDIAC Study population samples.

\section{Methods}

The health examinations for CARDIAC Study were carried out for about 200 in the total of males and females aged 48-56-years randomly selected according to CARDIAC Study protocol; height, weight and BP measured by using an automated BP measurement system were recorded, and fasting blood was collected for measuring total serum cholesterol (T-Cho) and HDL-cholesterol (HDL) to calculate atherogenic index (AI: T-Cho/HDL). $24 \mathrm{U}$ samples were collected by using aliquot cups to measure biomarkers of dietary intakes of sodium $(\mathrm{Na})$, potassium (K), T, M, and creatinine $(\mathrm{Cr})$. Cr was measured to calculate these dietary markers per body size by an alkaline picrate method and photometric reading. $M$ was measured by a colorimetric method. $T$ was measured by high performance liquid chromatography. The data of 3960 participants in 41 regions who succeeded in collecting $24 \mathrm{U}$ were used after excluding the Japanese where $\mathrm{T}$ intakes from seafood were extremely high and CHD mortalities were lowest. Using $24 \mathrm{U} \mathrm{T}$ and $\mathrm{M}$, the mean values of $\mathrm{T} / \mathrm{Cr}$ ratio (639.4) and the mean of $\mathrm{M} / \mathrm{Cr}$ ratio (82.8) were calculated, then all participants whose data were available were divided into four groups, group A (both $\mathrm{T} /$ $\mathrm{Cr}$ and $\mathrm{M} / \mathrm{Cr} \geqq$ mean), group $\mathrm{B}(\mathrm{T} / \mathrm{Cr} \geqq$ mean, $\mathrm{M} / \mathrm{Cr}<$ mean), group $\mathrm{C}$ ( $\mathrm{T} / \mathrm{Cr}<$ mean, $\mathrm{M} / \mathrm{Cr} \geqq$ mean) and group $\mathrm{D}$ (both $\mathrm{T} / \mathrm{Cr}$ and $\mathrm{M} / \mathrm{Cr}<$ mean), and the averages of risks, BMI, SBP, DBP, T-Cho, HDL and AI were compared between groups. Statistical analyses were conducted with SPSS 15.0J for Windows (SPSS Japan Inc., Tokyo, Japan). Between-group differences in BMI, SBP, DBP, T-Cho and AI were tested by the unpaired Student's $t$ test. Data are expressed as the mean \pm SEM. Values of $\mathrm{p}<0.05$ were considered significant.

\section{Results}

As indicated in Fig. 1, the participants with $\mathrm{T} / \mathrm{Cr} \geqq$ mean showed significant differences compared with the participants $\mathrm{T} / \mathrm{Cr}<$ mean in BMI $(24.56 \pm 0.12$ vs. 25.50 $\left.\pm 0.08 \mathrm{~kg} / \mathrm{m}^{2}, \mathrm{p}<0.001\right)$, SBP $(122.18 \pm 0.56$ vs. 124.12 $\pm 0.39 \mathrm{mmHg}, \mathrm{p}<0.01)$, DBP $(72.76 \pm 0.35$ vs. $74.76 \pm$ $0.25 \mathrm{mmHg}, \mathrm{p}<0.001)$, T-Cho (190.48 \pm 1.36 vs. 195.37 $\pm 1.10 \mathrm{mg} / \mathrm{dl}, \mathrm{p}<0.01)$ and $\mathrm{AI}(6.45 \pm 0.11$ vs. $7.70 \pm$ 0.09, p < 0.001). Between-group differences of BMI, DBP, and AI were highly significant $(\mathrm{p}<0.001)$.

As indicated in Fig. 2, the participants with $\mathrm{M} / \mathrm{Cr} \geqq$ mean showed all highly significant differences compared with the participants $\mathrm{M} / \mathrm{Cr}<$ mean in BMI $(24.27 \pm$ 0.11 vs. $\left.25.82 \pm 25.82 \mathrm{~kg} / \mathrm{m}^{2}, \mathrm{p}<0.001\right)$, SBP $(121.35$ \pm 0.51 vs. $124.97 \pm 0.41 \mathrm{mmHg}, \mathrm{p}<0.001)$, DBP $(71.96$ \pm 0.32 vs. $75.60 \pm 0.26 \mathrm{mmHg}, \mathrm{p}<0.001)$, T-Cho $(189.25 \pm 1.46$ vs. $196.57 \pm 1.05 \mathrm{mg} / \mathrm{dl}, \mathrm{p}<0.001)$ and AI $(6.62 \pm 0.11$ vs. $7.59 \pm 0.09, \mathrm{p}<0.001)$.

Fig. 3 indicated the average of cardiovascular risks in 4 groups, A, B, C and D, classified by the means of $\mathrm{T} / \mathrm{Cr}$ and $\mathrm{M} / \mathrm{Cr}$. Group A ( $\mathrm{T} / \mathrm{Cr}, \mathrm{M} / \mathrm{Cr} \geqq$ means) showed the lowest risks among four groups and showed highly significant differences compared with group $\mathrm{D}$ in the mean values of BMI $\left(23.81 \pm 0.18\right.$ vs. $26.15 \pm 0.11 \mathrm{~kg} / \mathrm{m}^{2}, \mathrm{p}<$ $0.001)$, SBP $(121.12 \pm 0.88$ vs. $125.81 \pm 0.50 \mathrm{mmHg}$, $\mathrm{p}<0.001)$, DBP $(71.16 \pm 0.53$ vs. $76.35 \pm 0.31 \mathrm{mmHg}$, $\mathrm{p}<0.001)$, T-Cho $(186.85 \pm 2.02$ vs. $197.96 \pm 1.29 \mathrm{mg} /$ $\mathrm{dl}, \mathrm{p}<0.001)$, AI $(5.63 \pm 0.14$ vs. $7.87 \pm 0.11, \mathrm{p}<$ $0.001)$. In addition, group $A$ showed significantly lower values compared with group $\mathrm{B}$ and $\mathrm{C}$ in $\mathrm{BMI}$ and $\mathrm{AI}$ and with group C in DBP.

\section{Discussion}

The present study confirmed our previous CARDIAC data analyses by the structural equation modeling (SEM) which indicated both $\mathrm{T} / \mathrm{Cr}$ and $\mathrm{M} / \mathrm{Cr}$ were strongly inversely related to CHD mortalities in males and females and $\mathrm{T} / \mathrm{Cr}$ was also inversely related to stroke in males and females [4]. Fig. 1 and 2 clearly demonstrate higher intakes of $\mathrm{T} / \mathrm{Cr}$ or $\mathrm{M} / \mathrm{Cr}(\geq$ mean) have significantly lower all cardiovascular risks, BMI, SBP, DBP, 

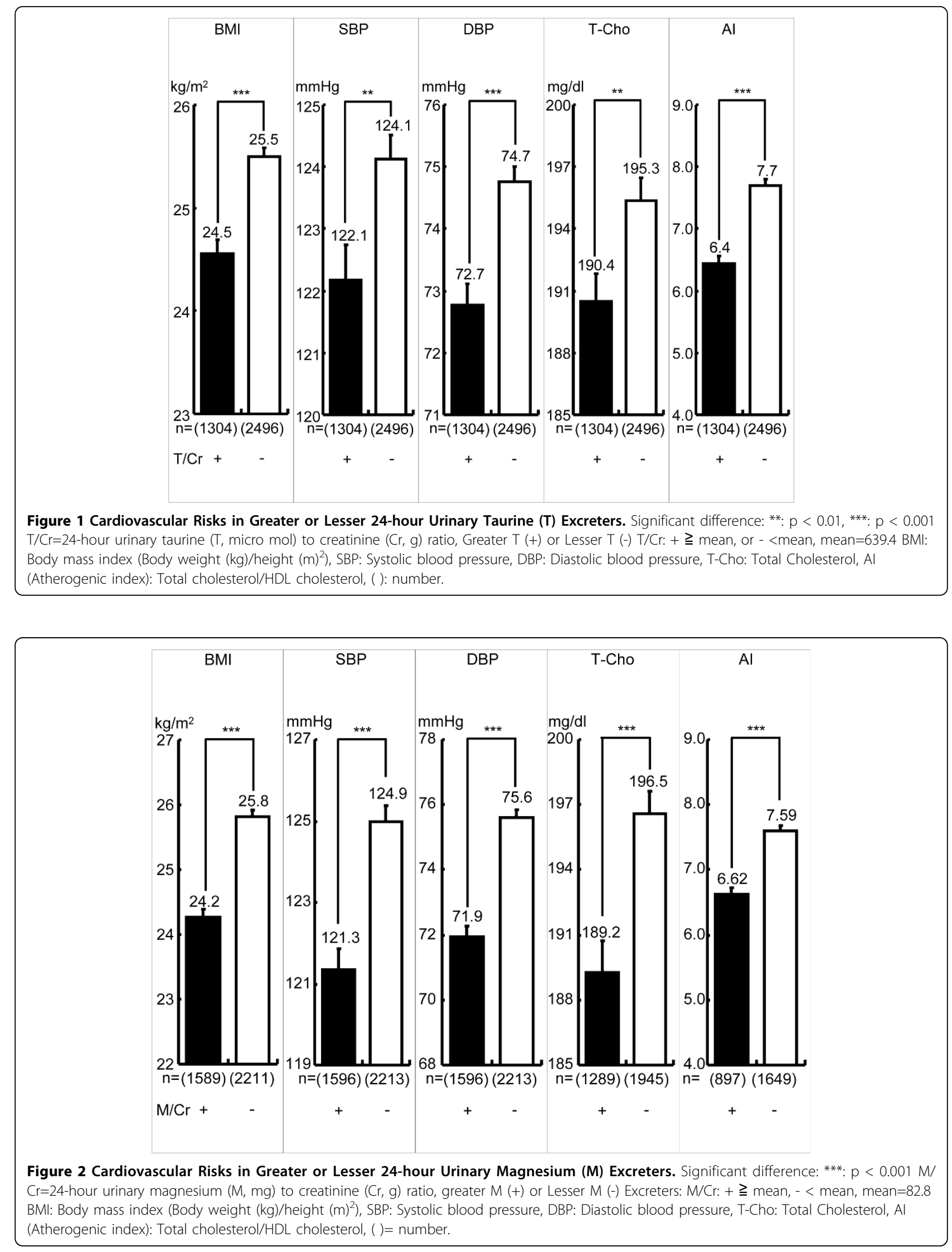


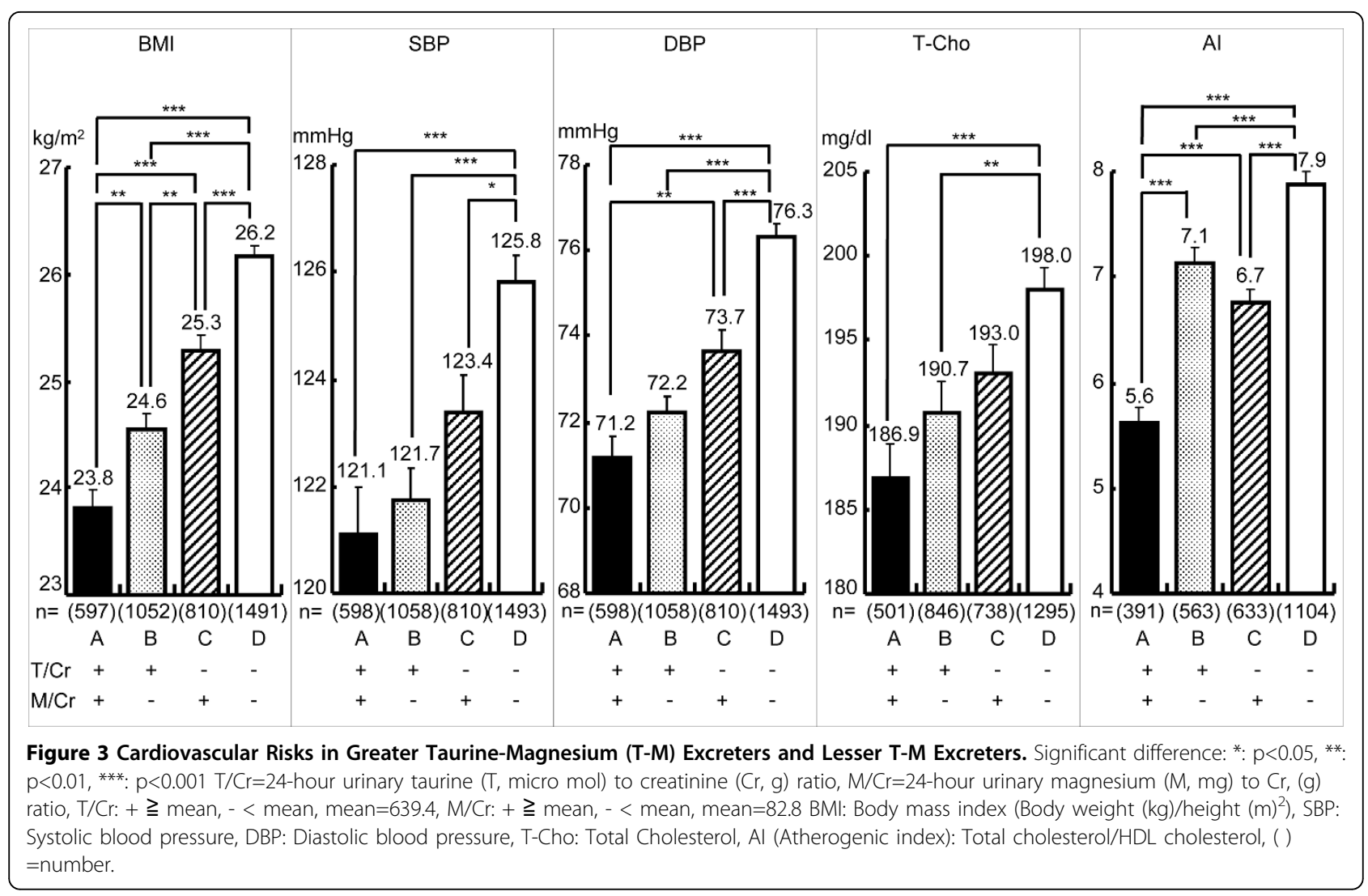

T-Cho and AI. Fig. 3 indicates that in the individuals whose $\mathrm{T} / \mathrm{Cr}$ and $\mathrm{M} / \mathrm{Cr}$ are both over the means, all risks, such as BMI, SBP, DBP and AI, are signficantly lower than in those whose $\mathrm{T} / \mathrm{Cr}$ and $\mathrm{M} / \mathrm{Cr}$ are both below the means, indicating enough intakes of both $\mathrm{T}$ and $\mathrm{M}$ should be the best dietary condition for reducing cardiovascular risks and preventing CHD and stroke as previously reported [3][4]. Since the data analyses were done in the present study regardless of genetic and environmental differences, diets to increase $\mathrm{T}$ and $\mathrm{M}$ intake, thus to increase $\mathrm{T} / \mathrm{Cr}$ and $\mathrm{M} / \mathrm{Cr}$ in $24 \mathrm{U}$, appear to beneficially affect cardiovascular physiology so to reduce cardiovascular diseases. As for the mechanisms of how $\mathrm{T}$ and $\mathrm{M}$ decrease the risks of cardiovascular diseases, numerous experimental and several clinical studies have been reported. For example, SBP and intracellular calcium $(\mathrm{Ca})$ in peripheral lymphocytes from stroke-prone spontaneously hypertensive rats (SHRSP) were significantly higher than in normotensive WisterKyoto rats (WKY), and intracellular M in SHRSP was significantly lower than in WKY [5]. Intracellular Ca overload acts as a trigger of cell death by inducing apoptosis and causes arteriosclerosis [6]. $\mathrm{T}$ improves the cardiovascular function through a variety of mechanisms including the improvement of lipid profiles, the modulation of intracellular $\mathrm{Ca}$ concentration, antioxidant effects and the antagonism of Ang II action [7]. Dietary T supplementation increases mRNA level of cholesterol 7alpha-hydroxylase to lower serum cholesterol in mice and rats [8]. In addition, $\mathrm{T}$ prevents high fat diet induced obesity with increased resting energy consumption [9]. $\mathrm{M}$ also activates $\mathrm{Na}-\mathrm{K}$ ATPase that controls intracellular mineral balance and contributes to the homeostasis of electrolytes in the cell [10]. It was experimentally demonstrated that intracellular $\mathrm{Ca}$ and $\mathrm{Na}$ was decreased by oral $\mathrm{M}$ supplementation which therefore lowered blood pressure in SHRSP [11] and hypertensive patients [12]. High $M$ supplementation lowered AI compared to low $\mathrm{M}$ diet group in rat [13]. $\mathrm{T}$ and $\mathrm{M}$ are involved in the homeostasis of intracellular $\mathrm{Ca}$ and $\mathrm{Na}$, thus to contribute to the maintenance of cellular structure and function $[10,14]$. When the vascular wall cells such as medial smooth muscle cells and endotherial cells are physiologically stabilized, peripheral circulation should be maintained well so that vascular lesions causing CHD and stroke are prevented, thus to contribute to a healthy long life. As for Klotho gene related to aging, it affects $\mathrm{Na}-\mathrm{K}$ ATPase and contributes to intracellular $\mathrm{Na}$ and $\mathrm{Ca}$ as $\mathrm{M}$ affects $\mathrm{Na}-\mathrm{K}$ ATPase. Klotho gene is involved in the maintenance of the $\mathrm{Ca}$ homeostasis [15], however, the underling mechanisms of intracellular ionic homeostasis related to $M$ and ageing 
are not yet clear. Anyhow, the present study indicates the intakes of the seafood containing $\mathrm{T}$ as well as seaweeds and nuts rich in $\mathrm{M}$ are expected to reduce overall risks related to cardiovascular diseases. Therefore, dietary customs that increase the intake of food containing $\mathrm{T}$ and $\mathrm{M}$ are expected to improve $\mathrm{BP}$ and blood lipid profiles and to decrease cardiovascular diseases.

\section{Conclusions}

The world-wide examination of $24 \mathrm{U} \mathrm{T}$ and $\mathrm{M}$ excretions as the marker of dietary $\mathrm{T}$ and $\mathrm{M}$ intakes of individual participants in the cross sectional CARDIAC health survey proved a highly significant inverse relationship to major cardiovascular risks as BMI, SBP, DBP, T-Cho and $\mathrm{AI}$, indicating combined intakes of $\mathrm{T}$ and $\mathrm{M}$ are important for CVD prevention.

\section{List of abbreviations used}

Al: atherogenic index, BMI: body mass index, Ca: Calcium, CARDIAC Study: Cardiovascular Diseases and Alimentary Comparison study, CHD: coronary heart diseases, Cr: creatinine, CVD: cardiovascular diseases, DBP: diastolic blood pressure, K: potassium, M: magnesium, Na: sodium, SBP: systolic blood pressure, SHRSP: stroke-prone spontaneously hypertension rates, T: taurine, T-Cho: total cholesterol, WKY: Wister-Kyoto rats, 24U: 24-hour urine.

\section{Acknowledgements}

This study was supported partly by Grant-in-Aid for science from The Ministry of Education, Culture, Sports, Science and Technology, Japanese Government and by the donations to WHO from many companies and over 300,000 individuals in total. Our appreciation should be extended to all participants in WHO-CARDIAC Study and to collaborating workers in worldwidely distributed study centers.

This article has been published as part as part of Journal of Biomedical Science Volume 17 Supplement 1, 2010: Proceedings of the 17th International Meeting of Taurine. The full contents of the supplement are available online at http://www.jbiomedsci.com/supplements/17/S1.

\section{Authors' contributions}

Y.Y. designed this study, T.T. contributed to the data analysis and the preparation of this article, M.M. helped epidemiological data analysis and H. M. contributed for carrying out epidemiological surveys.

\section{Competing interests}

The authors declare that they have no competing interests.

\section{Published: 24 August 2010}

\section{References}

1. Yamori Y, on behalf of the WHO-CARDIAC study group: Food factors for atherosclerosis prevention: Asian perspective derived from analyses of world wide dietary biomarkers. Exp Clin Cardiol 2006, 11:94-8.

2. Yamori Y, Liu L, Mizushima S, Ikeda K, Nara Y: CARDIAC Study Group: Male cardiovascular mortality and dietary markers in 25 population samples of 16 countries. J Hypertens 2006, 24:1499-505.

3. Yamori Y, Liu L, Mori M, Sagara M, Murakami S, Nara Y, Mizushima S: Taurine as the nutritional factor for the longevity of the Japanese revealed by a world-wide epidemiological survey. Adv Exp Med Biol 2009, 643:13-25.

4. Yamori Y, Mizushima S: A review of the link between dietary magnesium and cardiovascular risk. J Cardiovasc Risk 2000, 7:31-35.

5. Adachi M, Nara Y, Mano M, Ikeda K, Horie R, Yamori Y: Intralymphocytic free calcium and magnesium in stroke-prone spontaneously hypertensive rats and effects of blood pressure and various antihypertensive agents. Clin Exp Pharmacol Physiol 1993, 20:587-93.
6. Orrenius S, Zhivotovsky B, Nicotera P: Regulation of cell death: the calcium-apoptosis link. Nat Rev Mol Cell Biol 2003, 4:552-65.

7. Xu YJ, Arneja AS, Tappia PS, Dhalla NS: The potential health benefits of taurine in cardiovascular disease. Exp Clin Cardiol 2008, 13:57-65.

8. Chen W, Suruga K, Nishimura N, Gouda T, Lam VN, Yokogoshi H: Comparative regulation of major enzymes in the bile acid biosynthesis pathway by cholesterol, cholate and taurine in mice and rats. Life Sci 2005, 77(z):746-57.

9. Tsuboyama-Kasaoka N, Shozawa C, Sano K, Kamei Y, Kasaoka S, Hosokawa Y, Ezaki O: Taurine (2-aminoethanesulfonic acid) deficiency creates a vicious circle promoting obesity. Endocrinology 2006, 147:3276-84

10. Sontia B, Touyz RM: Role of magnesium in hypertension. Arch Biochem Biophys 2007, 458(z):33-9.

11. Adachi M, Nara Y, Mano M, Yamori Y: Effect of dietary magnesium supplementation on intralymphocytic free calcium and magnesium in stroke-prone spontaneously hypertensive rats. Clin Exp Hypertens 1994, 16:317-26

12. Hatzistavri LS, Sarafidis PA, Georgianos PI, Tziolas IM, Aroditis CP, Zebekakis PE, Pikilidou MI, Lasaridis AN: Oral magnesium supplementation reduces ambulatory blood pressure in patients with mild hypertension. Am J Hypertens 2009, 22:1070-5.

13. Takeda R, Nakamura T: Effects of high magnesium intake on bone mineral status and lipid metabolism in rats. J Nutr Sci Vitaminol 2008, 54:66-75.

14. Xu YJ, Saini HK, Zhang M, Elimban V, Dhalla NS: MAPK activation and apoptotic alterations in hearts subjected to calcium paradox are attenuated by taurine. Cardiovasc Res 2006, 72:163-74.

15. Imura A, Tsuji Y, Murata M, Maeda R, Kubota K, Iwano A, Obuse C, Togashi K, Tominaga M, Kita N, Tomiyama K, lijima J, Nabeshima Y, Fujioka M, Asato R, Tanaka S, Kojima K, Ito J, Nozaki K, Hashimoto N, Ito T, Nishio T, Uchiyama T, Fujimori T, Nabeshima Y: alpha-Klotho as a regulator of Calcium homeostasis. Science 2007, 316:1615-8.

doi:10.1186/1423-0127-17-S1-S21

Cite this article as: Yamori et al.: Low cardiovascular risks in the middle aged males and females excreting greater 24-hour urinary taurine and magnesium in 41 WHO-CARDIAC study populations in the world. Journal of Biomedical Science 2010 17(Suppl 1):S21.

\section{Submit your next manuscript to BioMed Central and take full advantage of:}

- Convenient online submission

- Thorough peer review

- No space constraints or color figure charges

- Immediate publication on acceptance

- Inclusion in PubMed, CAS, Scopus and Google Scholar

- Research which is freely available for redistribution 